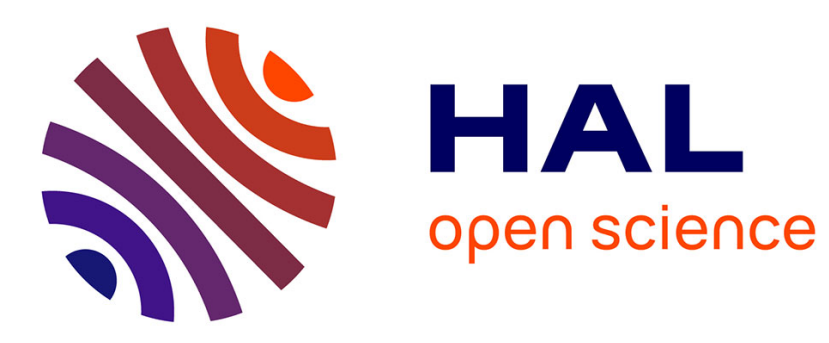

\title{
Power supply for a wireless sensor network: Airliner flight test case study
}

Paul Durand-Estèbe, Vincent Boitier, Marise Bafleur, Jean-Marie Dilhac, Sébastien Berhouet

\section{- To cite this version:}

Paul Durand-Estèbe, Vincent Boitier, Marise Bafleur, Jean-Marie Dilhac, Sébastien Berhouet. Power supply for a wireless sensor network: Airliner flight test case study. Journal of Energy and Power Engineering, 2014, 8 (12), pp.2058-2064. hal-01100084

\section{HAL Id: hal-01100084 https://hal.science/hal-01100084}

Submitted on 5 Jan 2015

HAL is a multi-disciplinary open access archive for the deposit and dissemination of scientific research documents, whether they are published or not. The documents may come from teaching and research institutions in France or abroad, or from public or private research centers.
L'archive ouverte pluridisciplinaire HAL, est destinée au dépôt et à la diffusion de documents scientifiques de niveau recherche, publiés ou non, émanant des établissements d'enseignement et de recherche français ou étrangers, des laboratoires publics ou privés. 


\section{Power Supply for a Wireless Sensor Network: Airliner Flight Test Case Study}

\author{
P. Durand Estebe ${ }^{1,2}$, V. Boitier ${ }^{1,3}$, M. Bafleur ${ }^{1,2}$, J-M. \\ Dilhac $^{1,4}$ \\ ${ }^{1}$ CNRS, LAAS, 7 avenue du colonel Roche, F-31400 Toulouse, \\ France \\ ${ }^{2}$ Univ de Toulouse, LAAS, F-31400 Toulouse, France \\ ${ }^{3}$ Univ de Toulouse, UPS, LAAS, F-31400 Toulouse, France \\ ${ }^{3}$ Univ de Toulouse, INSA, LAAS, F-31400 Toulouse, France
}

\author{
S. Berhouet \\ AIRBUS Flight Test Instrumentation \\ Toulouse, France \\ Contact : dilhac@laas.fr
}

\begin{abstract}
In this paper we present hands-on experience related to on-going implementation in aircraft of power supply for a wireless sensor network deployed for aerodynamic flight tests. This autonomous battery-free power supply is capturing, managing and storing primary energy from the environment, using solar light and photovoltaic cells. For practical purposes, it is also equipped with an auxiliary power input. The specifications are detailed, the general architecture is presented and justified, and test results are discussed.
\end{abstract}

Keywords- Flight Tests, Sensor Network, Solar Energy, Ultracapacitors.

\section{INTRODUCTION}

Air transport is now an essential pillar of modern society, and a major driver of global economic prosperity. Aviation forecasts show massive traffic increase, both for passengers and cargo, in the next decades. Therefore, air transport is facing various challenges such as fossil fuel consumption, pollutant and noise emission, air traffic congestion, business model, safety and security.

Technological innovations are therefore pursued in the area - among others - of engines, aircraft structural design, and structural new materials. Other innovations are taking place through the concept of More Electric Aircraft (MEA) that is an evolution starting with fly-bywire (a full electronic interface replaces the classical electro-mechanical interface between pilots and aircraft systems), and evolving through drive-by-wire (no more physical connection - mechanical, pneumatic or hydraulic - between sensor and actuator) to power-bywire (where pneumatic, mechanical and hydraulic power distributions are replaced by an electric power grid, except for propulsive power) [1]. It is worth to mention that MEA obviously calls for an increase in electrical power wiring size and complexity.

However, aviation's progress will also be carried out by an increased integration of cyber-physical systems into aircraft [2] for managing baggage, cargo, personal electronic devices, flight deck tasks and helping maintenance through Structural Health Monitoring
(SHM) [3]. There again the weight of wiring is likely to increase.

In that context, Wireless Sensor Networks (WSN) have been considered for various aeronautical applications, such as SHM [4] and flight tests. Each node of this network would perform sensing, data processing and wireless transmission of information. Such wireless networks will hopefully permit (often new) functions without the need of adding extra wiring to an already large burden.

However, these nodes need to be self-powered, many of the advantages of wireless sensor networking being obviously lost if external (i.e. wired) power sources were used. For this purpose, batteries offer a high energy density at low cost. However, there are critical drawbacks associated with the use of batteries: first environmental concerns and economical aspects associated with the replacement of primary batteries. Second, batteries (either primary or secondary) may be prohibited since the wireless nodes are often implemented in locations without temperature regulation that could result both in a drastically reduced yield together with safety issues. Fortunately, batteries can be avoided through the use of environmental energy capture allowing a solution for long term, deploy and forget, WSN. However, environmental energy transducers, unlike batteries, are not energy reservoirs, and energy buffer storage is mandatory whatever the context. We will explain why it can be achieved through electrostatic ultracapacitors (UC).

In this paper we present hands-on experience related to on-going implementation of energy harvesters in airliners for the purpose of flight tests. Even if aircraft manufacturers alone are involved in this application, this issue is critical as the implementation in the experimental aircraft of the extra wiring required for flight tests is complex and time-consuming.

In the second section we will describe the requirements of our application, and we will present the devised architecture in the third section. In a fourth section we will present preliminary results and identify directions for future work in the conclusion. 


\section{SYSTEM GLOBAL REQUIREMENTS}

In Fig. 1 the total electric cable lengths implemented in a car, a jet fighter and an airliner are compared. These lengths are also converted in kilometer per unit length of the car/aircraft as a measurement of complexity. From Fig. 1, it appears that fighter jets and airliners are very complex objects considering wiring, thus praising for wireless solutions when the deployment of new avionic is considered. As a consequence of such a choice, measurement data need of course to be transmitted wirelessly and the device has to be autonomous in energy. Specific components are therefore required to allow for this autonomy. Nevertheless, if stringent weight constraints (common in aeronautics) cannot afford these extra components, and if a power line runs close by, a connection to this line will be preferred.

Fig. 1 also gives the extra wiring related to flight tests, i.e. $60 \%$ of the regular wiring in the case of the A380. Generally speaking, this wiring is often difficult to implement and may be realized by bonding the cables using adhesive tapes for the instrumentation outside aircraft structure, or passing cables through multiple bulkheads by removing screws, bolts or rivets, or even by drilling holes when permitted (rarely allowed in composite materials) that is a cumbersome process, not to mention the multiplication of connectors. So, even if the application detailed in this paper is of interest to flight test departments of aircraft manufacturers only, it is a critical issue because flight-testing is essential to validate a design and obtain certifications from government agencies, while being expensive, complex and timeconsuming.

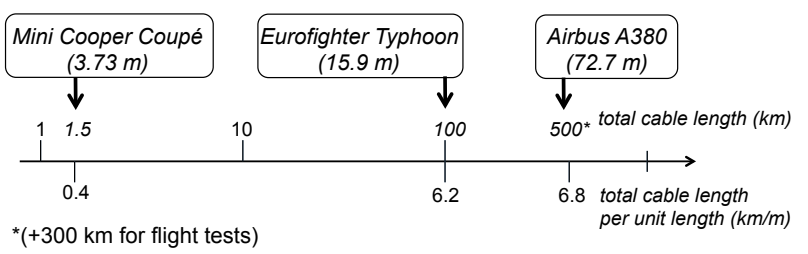

Fig. 1. Wiring complexity for various means of transportation (estimations).

Among the typical measurements performed during flight-tests, are pressure sensing at tens of positions around wings, tail, rudder... For this purpose, pressure gloves, themselves accommodating tens of sensors are affixed to the aircraft outside skin together with cables connecting them to data loggers. The replacement of this apparatus by WSN (Fig. 2) would reduce design load, installation and relocation time.

Considering that a wireless implementation is chosen, the simplest way of gaining autonomy in energy is to use an energy reservoir such as a primary electrochemical battery. Such batteries are products of a mature industry: they offer a high energy density - and even a high power density when in parallel with an ultracapacitor - together with a low self-discharge. But, as already mentioned, their performance is strongly altered by the extreme (low) temperature encountered outside aircraft at cruise altitude, not to mention safety issues raised by some technologies.

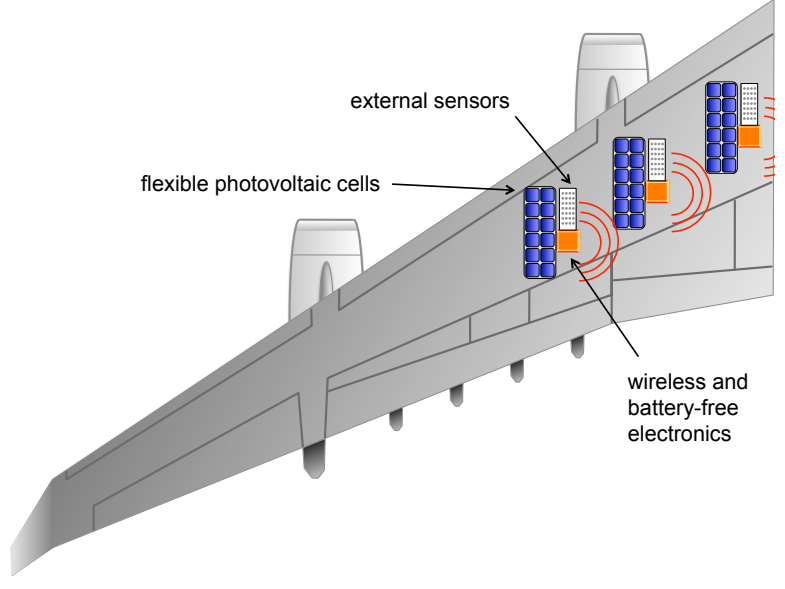

Fig. 2. Schematic of pressure gloves affixed on top of a wing. The system here is supposed wireless.

Energy capture from the environment is then mandatory and fortunately, for the considered application, solar energy can be harvested because i) the sensors are located outside the aircraft ii) for security and simplicity reasons most flight tests are done at daylight.

It is worth mentioning that energy storage is here still required for two reasons: first to accommodate for transient power surges from the load exceeding the mean electrical harvested power, and then to maintain the energetic autonomy in the case of an intermittent environmental source as will be illustrated later. UC performing electrostatic storage may do the job; while being affected by extreme positive ambient temperatures similarly to most batteries, they exhibit better performance at low temperature and provide an almost infinite lifetime. Consequently, they do not need any replacement. Because of their low energy density, they are safer than batteries, and supposed to be more environment-friendly. Unfortunately, they are impaired by strong self-discharge especially during the first hours [5] and efficient long-term storage is not feasible. Finally, they exhibit a charge-dependent output voltage asking for a voltage regulator when used for circuit biasing, and suffer from a low maximum voltage rating (as low as $2.2 \mathrm{~V}$ for some models tested below) related to the dielectric properties of the electrolyte.

Solar energy is qualitatively one of the most abundant ambient energy and easily translates itself into electricity through mature and still progressing technology, while $\mathrm{UC}$ are an appealing alternative to batteries but, for supplying power to the above pressure sensors, specific requirements from the environment are to be fulfilled. They are two fold.

First, the power supply (comprising photovoltaic cells, maximum power point tracking circuit, energy management devices and buffer storage ultra capacitor) 
must be both very thin not to disturb the streamline flow, and globally flexible to adapt to curvy profiles. Considering areas, flexibility main impact is on photovoltaic (PV) cells, restricting the choice to less efficient cell technologies.

Then, all devices must operate at low temperature (down to $-55^{\circ} \mathrm{C}$ ) and reduced atmospheric pressure $(200 \mathrm{hPa})$; fortunately low temperatures have a favorable impact on PV cell yield. Conversely, references of energy buffer UC correctly performing at such extreme temperatures and ambient pressure must be identified.

Finally the amount of power delivered to the sensing and communicating devices has to be assessed, given the sampling frequency, number of sensors and wireless data rate.

This system development has to be carefully carried out, considering the environment (i.e. solar flux vs. altitude, time, season, location...) and the harvesting system itself (photovoltaic cells and associated electronics). However, the objective is not to install a permanent system aiming at monitoring a critical parameter during the airliner lifetime, but to deploy a temporary test rig using WSN. Long-term dependability is then not at stake.

In the next section we will now detail quantitative requirements and derive the general architecture for the power supply unit.

\section{GENERAL ARCHITECTURE}

General requirements of our application translate into the following. The flexible power supply dedicated to be bonded to the extrados of an aircraft wing (see Fig. 2):

- uses solar cells as main source of energy,

- is less than a few millimeters in thickness,

- delivers a mean electrical power of at least $2 \mathrm{~W}$ under $5 \mathrm{~V}$ (later shifted to $48 \mathrm{~V}$, see below), under modest (cloudy) illumination,

- operates between $-50^{\circ} \mathrm{C}$ (cruise altitude) and $+85^{\circ} \mathrm{C}$ (parking under direct sunlight), and down to $200 \mathrm{hPa}$ (i.e. 35000 feet),

- incorporates an energy storage (UC) unit in order to deal with transient absence of sunlight, the targeted autonomy being 1 hour,

- is capable of autonomous start-up, with the help of solar cells alone, the storage unit being empty [6].

The typical use case is illustrated in Fig. 3.

\begin{tabular}{|c|c|c|c|c|c|c|c|c|}
\hline Time & (3) & $E^{3}$ & 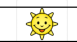 & 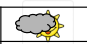 & Ens & $E 3$ & 舫 & $3^{x^{\circ}}$ \\
\hline operation & park & $\begin{array}{l}\text { taxi + } \\
\text { take off }\end{array}$ & cruise & $\begin{array}{l}\text { land }+ \\
\text { taxi }\end{array}$ & park & $\begin{array}{l}\text { taxi }+ \\
\text { take off }\end{array}$ & cruise & $\begin{array}{l}\text { land + } \\
\text { taxi }\end{array}$ \\
\hline $\begin{array}{l}\text { power } \\
\text { source }\end{array}$ & ground & storage & PV & storage & ground & storage & PV & storage \\
\hline $\begin{array}{l}\text { flight } \\
\text { profile }\end{array}$ & ground & $\begin{array}{l}\text { ground } \\
\text { + up }\end{array}$ & $\begin{array}{l}\text { FL } 200 \\
\text { to } 350\end{array}$ & $\begin{array}{l}\text { down }+ \\
\text { ground }\end{array}$ & ground & $\begin{array}{l}\text { ground } \\
\text { + up }\end{array}$ & $\begin{array}{l}\text { FL } 200 \\
\text { to } 350\end{array}$ & $\begin{array}{l}\text { down }+ \\
\text { ground }\end{array}$ \\
\hline
\end{tabular}

Fig. 3. Power supply: example of a use case as given by the final user. FL stands for Flight Level, and roughly corresponds to an altitude in hundreds of feet.

Considering the above specifications, we devised the general architecture depicted in Fig. 4. The load corresponds to a datalogger used to manage the pressure measurement sensors; its typical characteristics are in the range $48 \mathrm{~V} / 2 \mathrm{~W}$.

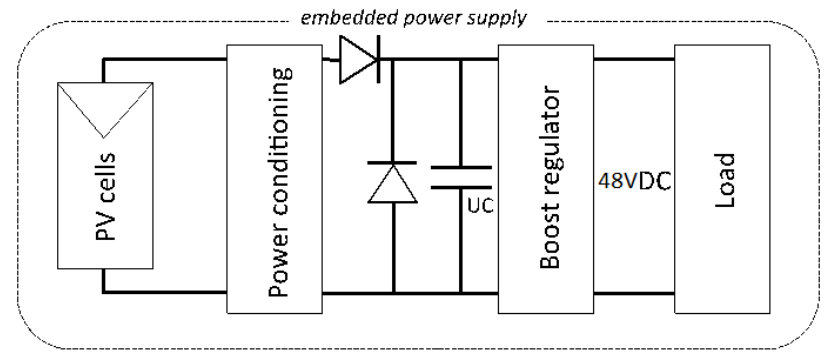

Fig. 4. Power supply: general architecture. Power conditioning includes MPPT (Maximum Power Point Tracking), UC overvoltage protection and buck-boost regulator command (not shown).

The PV cells are connected to a power conditioner whose task is to optimize the energy transfer through Maximum Power Point Tracking (MPPT) and to store the energy in the UC. It also protects the UC from overvoltage. A blocking diode is inserted between power conditioning and UC to prevent the latter from discharging itself when photovoltaic cells are not delivering any energy.

The UC is connected to the load through a boost regulator. In a start-up phase, as long as regulator input voltage is below min operating value, power conditioner does not bias the regulator, in order to speed-up UC charge.

\section{EXPERIMENTAL RESULTS}

For the solar cell testing, key points were a flexible photovoltaic panel with the best efficiency at low light, as the system has to power the load even in cloudy weather. We used thin film solar cells, reaching 9\% efficiency at $72 \mathrm{~W} / \mathrm{m}^{2}$. Fig. 5 shows flexibility and main characteristics of the selected PV panel (SolbianFlex SP50-L).

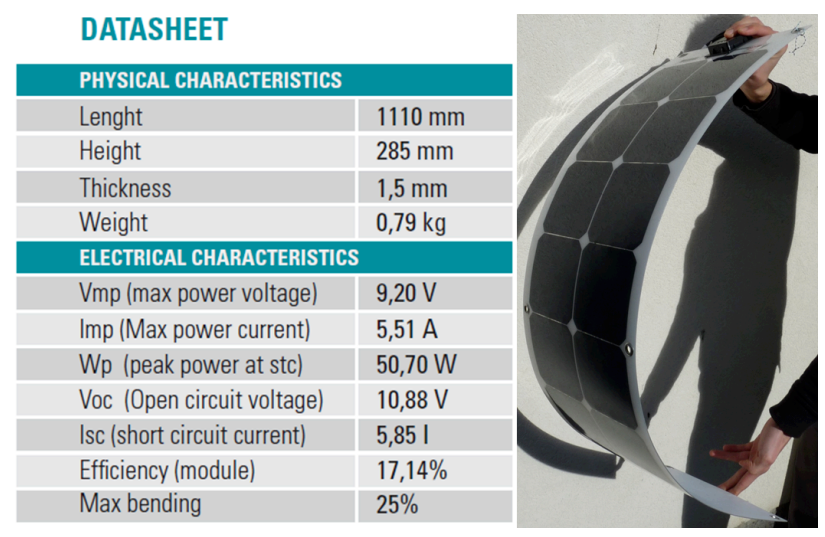

Fig. 5. Main characteristics of SolbianFlex SP50-L. 
Considering energy storage, we tested 8 types of UC from six different manufacturers in climatic chambers to identify technologies compatible with our requirements. According to data sheets, the operating temperatures were ranging between $\left[-20,+70^{\circ} \mathrm{C}\right]$ and $\left[-40,+85^{\circ} \mathrm{C}\right]$ depending upon model. In other words, no model was initially rated for the extended range of $\left[-50,+85^{\circ} \mathrm{C}\right]$.

With a SP-240 4A potentiostat from BioLogic, we first submitted the devices to constant current charges and discharges in a Temptronic Thermostream climatic chamber, at temperatures between $-50^{\circ} \mathrm{C}$ and $+100^{\circ} \mathrm{C}$. Then, at $-50^{\circ} \mathrm{C}$ only, we submitted them to an identical charge and discharge cycle, at $200 \mathrm{hPa}$, in another climatic chamber (CLIMATS EX5423-TE).

During these two sets of experiments, we plotted the $\mathrm{V}(\mathrm{t})$ curves and the drift vs. temperature (see the example of Fig. 6).

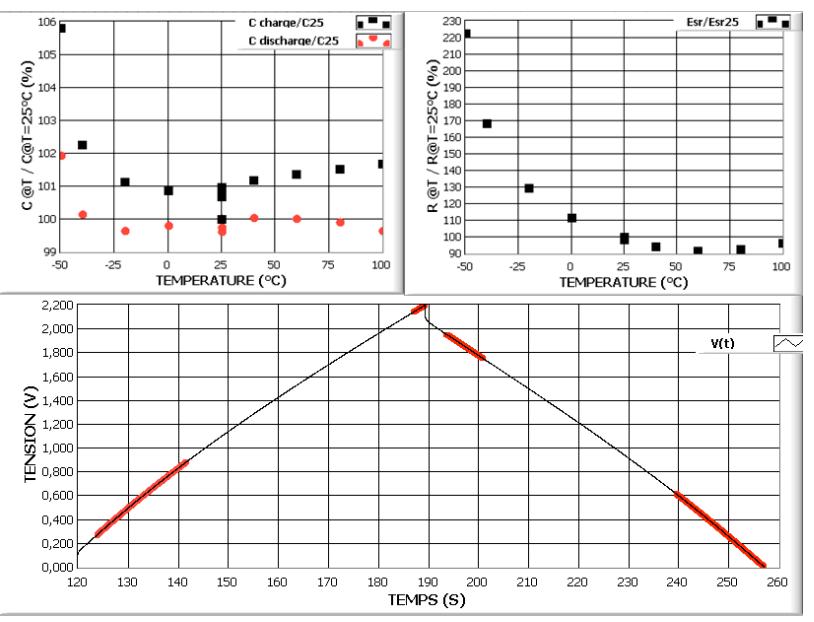

Fig. 6. Variations of capacitance and ESR with temperature and example of charge and discharge of a Maxwell PC10 ultracapacitor. The voltage drop after the peak is due to the equivalent serie resistor of the UC.

Finally, we measured the self-discharge performance in open circuit of all models by plotting, during more than three days, the output voltage vs. time after an initial charge at $2.2 \mathrm{~V}$.

From the above tests we made a trade-off and identified the best reference, also considering both thickness and capacitance per $\mathrm{cm}^{2}$, in order to comply with the already mentioned thickness requirements and to minimize the area devoted to energy storage. Nevertheless, the targeted autonomy asked for the association of multiple UCs.

We then devised an electronic circuit (see Fig. 7) incorporating all devices shown in Fig. 4 except PV cells and the ground power supply. We carefully limited the thickness of the circuit, specifically that of the inductor.

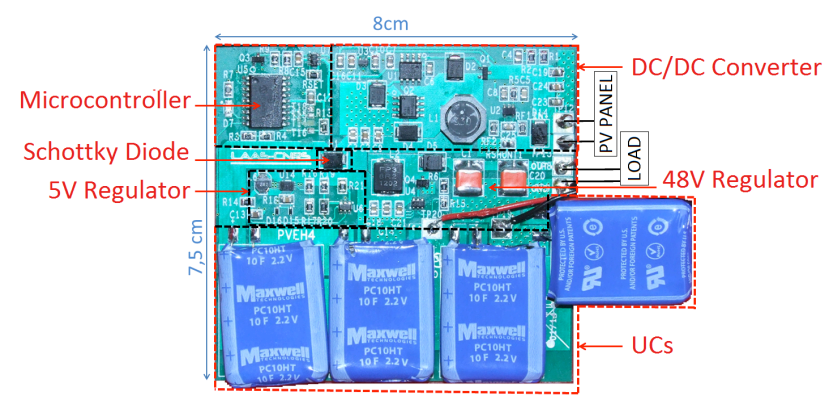

Fig. 7. Power management board.

Many electronic devices, such as the microcontroller and the converters, require a bias voltage. For this purpose, a 5 volts LDO voltage regulator TPS71550 (Vout $=5 \mathrm{~V}, 6 \mathrm{~V} \leq \mathrm{Vin} \leq 24 \mathrm{~V}$ ) is directly connected to solar panel. Consequently, if the photovoltaic voltage falls under $6 \mathrm{~V}$, the Power Conditioning device in between photovoltaic panel and UCs is cut off and, the load is powered by UCs only. This Power Conditioning is a DC/DC synchronous buck converter in series with a blocking Schottky diode.

To deal with various atmospheric conditions, a MPPT algorithm is implemented in a PIC18F1220 microcontroller based upon fractional Open-Circuit Voltage Method with the advantage of using one sensor only. The open circuit voltage of photovoltaic cells is measured every 10 seconds. When the UCs voltage reaches almost its maximum rated value, the algorithm will move from MPPT mode to UC voltage regulation mode.

The output stage was first designed to deliver a $5 \mathrm{~V}$ output. Because of late changes in specifications requiring a $48 \mathrm{~V}$ output, we simply add a $5 \mathrm{~V}$ to $48 \mathrm{~V}$ boost regulator due to a lack of time for another solution.

A boost regulator (LT3539) is placed between the UCs and the load in order to regulate the output voltage to $5 \mathrm{~V}$. The input voltage range of this component is $2.3-4.4 \mathrm{~V}$ when it supplies $2 \mathrm{~W}$.

We used LT3539 Shutdown pin to keep the output disabled and to allow the photovoltaic panel to first charge UCs [6]. When the UCs terminal voltage reaches $4 \mathrm{~V}$ (the higher the voltage across the UCs, the better the LT3539 efficiency is), the LT3539 is turned on by a command from the microcontroller. Then the solar panel will both power the load and charge the UCs whenever the sun is shining strongly enough. If not, the UCs alone will power the load.

The $5 \mathrm{~V}$ to $48 \mathrm{~V}$ conversion is realised by a MAX 1523 boost controller, supplied by the LT3539 output, and thus is only activated when the LT3539 is on.

Finally, for the bonding onto the aircraft wing, the electronic power management board together with ultracapacitors was inserted into a thin plastic packaging whose shape was designed in order to minimize disorders induced to the airflow. Pictures of this arrangement are shown in Fig. 8. Paths for cables to the photovoltaic panel and the sensors are set up in the beveled edges of the packaging.

The overall system supplies the $2 \mathrm{~W}$ load from a solar irradiance as low as $80 \mathrm{~W} / \mathrm{m}^{2}$ using a $0.32 \mathrm{~m}^{2}$ SolbianFlex 
SP50L PV panel, rated with peak power of 50W.
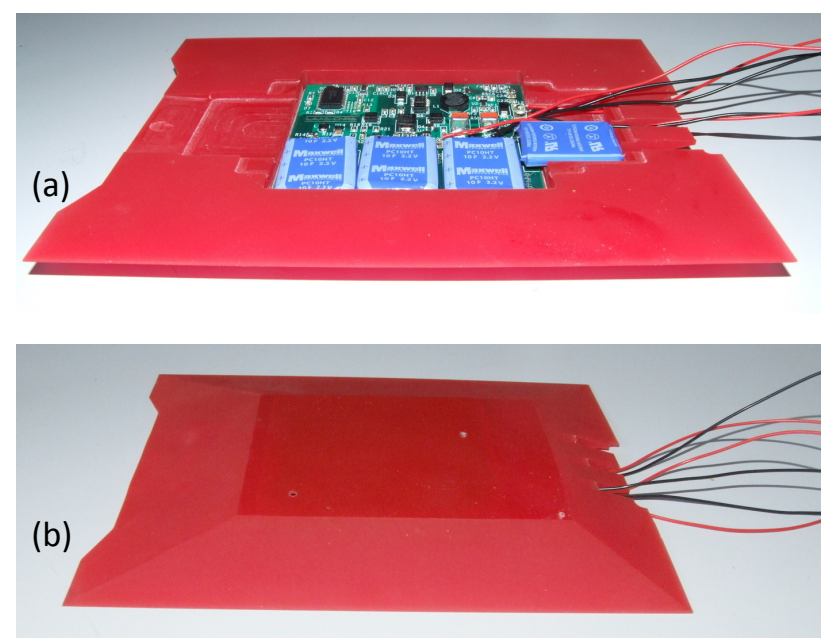

Fig. 8. (a) power management module and ultracapacitors inserted into package (b) package as it will appear once bonded to the aircraft wing.

\section{CONCLUSIONS}

We have reported the design details of a power supply for a wireless sensor network deployed for airliners inflight tests. The system has been successfully tested on ground. Real flight-tests are scheduled to confront with real environment.

\section{REFERENCES}

[1] J. A. Rosero, J. A. Ortega, E. Aldabas, L. Romeral, "Moving Towards a More Electric Aircraft," IEEE A\&E Systems Magazine, vol. 22, no. 3, pp. 3-9, 2007.

[2] K. Sampigethaya, R. Poovendran, "Aviation Cyber-Physical Systems: Foundations for Future Aircraft and Air Transport," Proceedings of the IEEE, vol. 101, no. 8, pp. 1835-1855, 2013.

[3] L. G. Dos Santos, "Embraer Perspective on the Introduction of SHM into Current and Future Commercial Aviation Programs," Structural Health Monitoring 2011, Proceedings of $8^{\text {th }}$ IWSHM, DEStech Publications, pp. 19-29, 2011.

[4] J-M. Dilhac, M. Bafleur, "Energy Thermo Generation in Aeronautics for Battery-free Wireless Sensor Networks," Thermoelectrics Goes Automotive II, Daniel Jänsch ed., Expert Verlag, pp. 135-143, 2013.

[5] Y. Diab, P. Venet, H. Gualous, G. Rojat, "Self-Discharge Characterization and Modeling of Electrochemical Capacitor Used for Power Electronics Applications," IEEE Trans. on Power Electronics, vol. 24, no. 2, pp. 510-517, 2009.

[6] V. Boitier, P. Durand Estebe, R. Montheard, M. Bafleur, J-M. Dilhac, "Under voltage lock-out design rules for proper start-up of energy autonomous systems powered by supercapacitors", Proceedings of PowerMEMS International Conference, London, 2013. 